\title{
The Rainwater Management Strategy in Kunming Area
}

\author{
Jianwu Ma ${ }^{1, a}$,Yuanyuan Zhang ${ }^{2, b}$ \\ ${ }^{1}$ Gold Mantis School of Architeture, Soochow University, Suzhou,Jiangsu Province,China \\ ${ }^{2}$ Gold Mantis School of Architeture, Soochow University, Suzhou,Jiangsu Province,China \\ a $478646560 @$ qq.com, ${ }^{\text {b445229703@qq.com }}$
}

\section{Keywords:Kunming,runoff,green space,stormwater management,strategy}

Abstract: Based on the meteorological data, Kunming located in the subtropical plateau monsoon climate area, is proved to have clear dry and wet seasons with aboundant precipitation. The light and heavy rain have a great influence on surface runoff.The average annual evaporation is more than the precipitation which results in the soil drought and water shortage every year.According to the measured data of different vegetation configurations in green spaces, it shows that the main soil type in Kunming is light clay soil, and that under the condition of steady infiltration, the cumulative infiltration is more than one year return period precipitation but less than twenty year return period precipitation.By analyzing the efficiency of rain interception by vegetation, it shows that vegetation have obvious effects on delaying flood peak runoff and increasing soil moisture content.Using the Small Storm Event Hydrological Model and Water Balance Formulation to analyse rainfall, runoff, infiltration and evaporation synthetically,the law of runoff can be figured out. Four rainwater management strategies are put forward on based on the above:Simulate nature to make the land work.Manage rainwater in the split-flow way and utilize different green spaces to intercept rainwater from the Source.Implement the suitable practical rainwater management technology with LID in Kunming. Combine engineering and artful design in management.

\section{Introduction}

Rain is the gift of God to us. Droughts and floods are usually caused by lacking of effective rainwater management. China has a vast territory where climatic and urban conditions are variant.To explore a suitable rainwater management strategy based on the specific conditions and fundamental analysis can avoid new or even greater environmental problems resulting from blind construction activities.

Based on the meteorological data provided by the Meteorological Bureau of Yunnan Province, this paper chose five meteorological stations in Kunming to carry out lots of analysis to get the basic law of rainfall and took five parks as samples to carry on the soil infiltration law and rain intercepting efficiency of vegetation. Based on the analysis above,the necessity and goal of using the green space for rainwater management can be drawn, and as well the basic rainwater management strategy.

\section{Analysis of Basic Conditions in Kunming Area}

The law of precipitation and evaporation in Kunming area.Yunnan Province is located in the southwest border of China, of which the Tropic of Cancer runs through the south. The north of Yunnan is the wide Asian continent, and the south of it is the vast Bay of Bengal and the South Sea.Yunnan is in the intersectional region between East Asian monsoon and the South Asian monsoon. Influenced by the northwestern Qinghai-Tibet Plateau large terrain, it is generally located in the Hengduan Mountain Area among the high mountains and deep gullies and the south and east of it is the Yunnan-Guizhou Plateau.The unique geographical environment results in its three significant characteristics: the monsoon climate, three-dimensional climate and low latitude climate.

The data analysis of five stations from 2001 to 2011 presents that the average annual precipitation ranges from $681.5 \mathrm{~mm}$ to $981.8 \mathrm{~mm}$. It has clear dry and rainy seasons and extremely uneven rainfall distributions during the year. The dry season is from November to April,during which the rain is scarce and the precipitation accounts for only $12.3 \%-15.2 \%$ of the annual precipitation. The rainy 
season is between May and October with abundant precipitation. (Table 1)The recent 11-year data shows that most days in a year is rainless. In the process of rain, the light rain event(nearly 90 days) is the main kind among all.The frequency of the light rain is the highest,in which events lasting for a day occur with the most frequency.The frequency of moderate rain takes the second place, in which there are few events more than 2 days. The frequency of heavy rain and rainstorm is the lowest and most of the events last less than a day.Most of rainstorm events have short durations and are low-frequency, but with high intensity and it contributes much. The precipitation of rainstorm is abundant,but it lasts a fairly long period with no rain.It is easy to form vast runoff in a short period with floods happening.

Table1. Frequency for different precipitation grade and frequency of duration time (days)

\begin{tabular}{|c|c|c|c|c|c|c|c|c|c|}
\hline $\begin{array}{l}\text { Precipitation } \\
\text { Grade }\end{array}$ & $\begin{array}{l}24 \mathrm{~h} \text { standard } \\
(\mathrm{mm})\end{array}$ & $\begin{array}{l}\text { Average days } \\
\text { in a year(d/a) }\end{array}$ & $\begin{array}{l}\text { Average Annual } \\
\text { precipitation } \\
\text { (mm/a) }\end{array}$ & $\begin{array}{l}\text { Average Daily } \\
\text { Precipitation } \\
\text { (mm/d) }\end{array}$ & $\begin{array}{l}\text { Frequency } \\
(\%)\end{array}$ & $\begin{array}{l}\text { 1 Day } \\
\text { (Time) }\end{array}$ & $\begin{array}{l}\text { 2 Days } \\
\text { (Time) }\end{array}$ & $\begin{array}{l}\text { 3 Days } \\
\text { (Time) }\end{array}$ & $\begin{array}{l}\geq 4 \text { Days } \\
\text { (Time) }\end{array}$ \\
\hline Rainless & 0 & 246.1 & 0 & 0 & 67.4 & & & & \\
\hline Light Rain & $0.1-9.9$ & 90.7 & 236.4 & 2.6 & 24.9 & 31.7 & 13.8 & 4.5 & 3.6 \\
\hline Moderate Rain & $10-24.9$ & 18.3 & 294 & 16.1 & 5.0 & 14 & 1.5 & 0.6 & 0 \\
\hline Heavy Rain & $25-49.9$ & 8.4 & 271.6 & 32.5 & 2.3 & 7.1 & 0.6 & 0 & 0 \\
\hline $\begin{array}{l}\text { Rainstorm and } \\
\text { above }\end{array}$ & $\geq 50$ & 1.5 & 109.6 & 70.9 & 0.41 & 1.6 & 0.1 & 0 & 0 \\
\hline
\end{tabular}

Evaporation is crucial in measuring the state of water balance. Any series of processes related to water and heat should take it as the consumption of water into consideration.Most of time in a year in

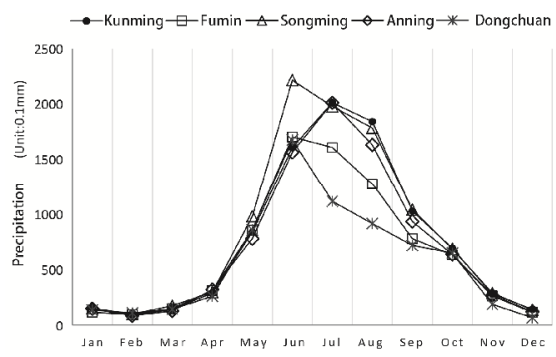

Figure 1: Average monthly precipitation in Kunming area from 2001 to 2011

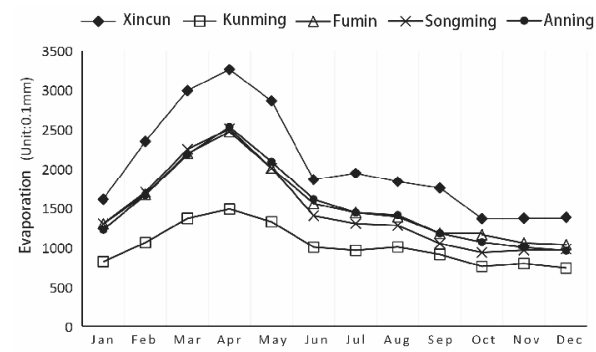

Figure 2:Average monthly evaporation in Kunming area from 2001 to 2011

Kunming is sunny and the average annual sunshine duration is 2445.6 hours. Solar projection angle is large all year round and the total annual radiation amounts to $129.78 \mathrm{kcal} /$ square centimeter[1].Especially in spring,autumn and winter,it is dry and rainless with gale and strong evaporation.The evaporation data of five samples in the same period shows the significant monthly gap.(Figure 1,Figure 2) Except June,July and August,the evaporation is more than the precipitation.

Experiments and Analysis of Soil Properties in Kunming Area. Surface runoff, runoff peak and time of runoff on the ground are directly related to precipitation and underlying surface. Soil can absorb, purify and store stormwater. Through Double Loop Infiltration Experiment of different plant configurations in different plots, the Kostiskov Model, the Hoston model, the Philip Model and the general empirical formula are used to fit soil infiltration rate to study infiltration law. The results shows [2] that the soil physical sand content is between $28 \%$ and $33 \%$. The average bulk density is $1.28 \mathrm{~g} / \mathrm{cm}^{3}$ and the total porosity is $49.9 \%$ in which the capillary porosity is $12.5 \%$.The main soil 
type is light clay in the Kaganski soil classification system, with good capability of moisture and fertilizer conservation, but the permeability is the medium to inferior type. Under the condition of stable infiltration,the average infiltration is much larger than one year return period precipitation but less than twenty year return period precipitation.

Measurement and Analysis of Vegetation Interception Efficiency to Rainfall.Most of the plant configurations in Kunming include arbors, shrubs and grasses. The canopy interception of selective 45 groups of plants shows that plant configurations of double-layer can intercept rainwater twice which have better interception capacity than single-layer.The penetration under the canopies increases with the increase of rainfall, showing a significant linear relationship. The more intense rainfall is, the lower soil water content under the shrubs is. Three days after rainfall by sampling the soil under the canopies of the same plants, it is found the soil moisture content under the arbors with shrubs changes inconspicuously, but it is significantly lower than that in the previous measurement results under the shrubs, which shows that configurations of arbors and shrubs have better water conservation capacity and shrubs are inferior. When rainfall intensity is between $0 \mathrm{~mm} / \mathrm{h}$ and $2 \mathrm{~mm} / \mathrm{h}$,canopy interception and interception rate are the highest. And when it is between $6 \mathrm{~mm} / \mathrm{h}$ and $8 \mathrm{~mm} / \mathrm{h}$,canopy interception is the lowest. Interception rate is the highest during the interval between $24 \mathrm{~h}$ and $48 \mathrm{~h}$ after the previous rainfall. Throughfall under the selective plants increases with the increase of rainfall, namely, the longer rainfall lasts, the more throughfall is. (Figure 3 , Figure 4)

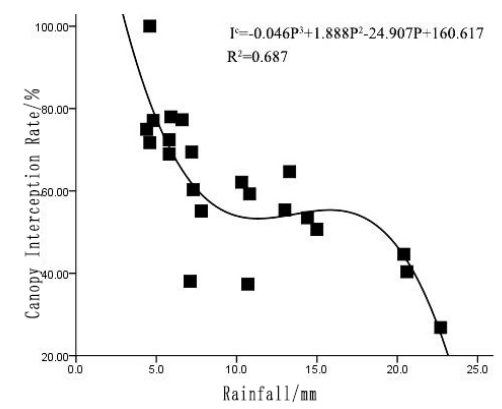

Figure 3: Relation between canopy interception and rainfall of single-layer plant configurations

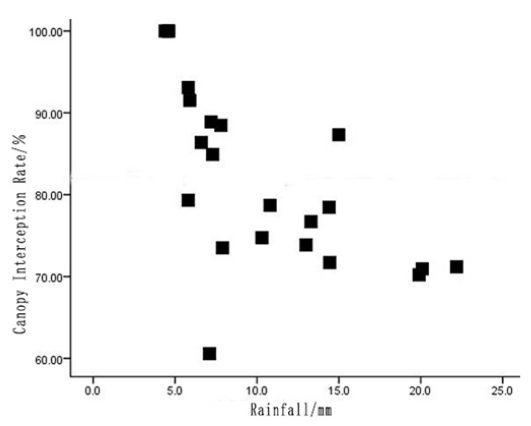

Figure 4: Relation between canopy interception and rainfall of double-layer plant configurations

\section{Necessity of Rainwater Management in Kunming Area}

Water-lacking Soil and Wasted Runoff. The SCS-CN Method,Reasoning Algorithm and the Small Storm Event Hydrological Model are usually used on runoff estimation.Rainfall is converted into runoff by the former two methods, but correct results can not be calibrated. This paper uses the Small Storm Event Hydrological Model to calculate the runoff according to runoff loss under different underlying surface, which is more objective and relatively accurate.

The average annual runoff can be calculated according to relevant data of the light clay.This paper takes $39.89 \%$ as green space ratio, 0.95 as the impermeable surface runoff coefficient and 0.2 as the park green space runoff coefficient [3].Nature manages rainwater in several ways including evaporation, infiltration,runoff and so on to maintain water circulation and balance.Rainfall, evaporation, runoff and infiltration are calculated based on $\mathrm{P}=\mathrm{R}+\mathrm{I}+\mathrm{E}$ (P for precipitation, $\mathrm{R}$ for 
surface runoff, I for infiltration, E for evaporation). (Figure 5 ) The negative infiltration shows that the evaporation is far greater than the precipitation, rather than that no rain infiltrates into the soil. As intense evaporation takes lots of water from the surface each year,water shortage in the soil increases year by year resulting in increasing risk of droughts. It is estimated that $898.6 \mathrm{~mm}$ to $2221.2 \mathrm{~mm}$ water should be used to replenish the soil every year to maintain a water balance. The analysis above shows that $443.5 \mathrm{~mm}$ to $639.0 \mathrm{~mm}$ runoff from rainfall is now drained to the pipes in vain.If runoff is carefully managed to replenish the soil, droughts and water shortage will be alleviated.

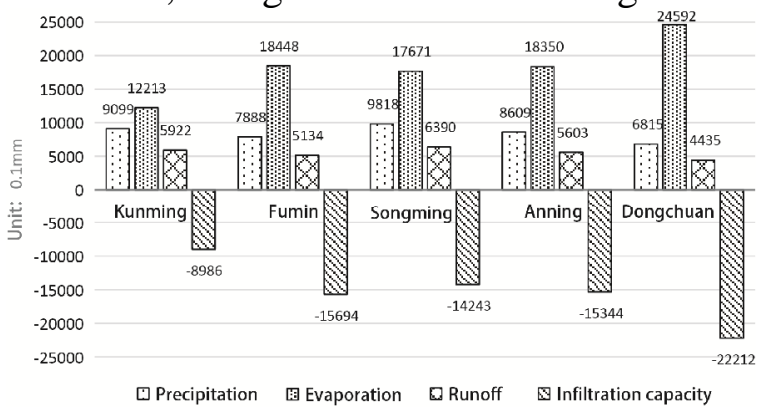

Figure 5: Average annual rainfall,runoff,evaporation and infiltration capacity in Kunming area from 2001-2011

Large Rainfall, Concentrated Precipitation,High Frequency of Light Rain and Obvious Infiltration and Interception Efficiency. There is more than $86 \%$ of rainfall from the rainy season in Kunming,but the distribution of abundant rainfall is extremely uneven. There is nearly $2 / 3$ of a year with no rain, though concentrated rainfall contributes about $1000 \mathrm{~mm}$ of rainfall only in a quarter of a year.Compared with the light rain event,the frequency of moderate and heavy rain is relatively low and the duration is shorter.It is suitable for the gradual interception and infiltration by green spaces. The average infiltration in an hour is much larger than one year return period precipitation in an hour in the light clay.The efficiency of interception is obvious.Double-layer plant configurations show better capacity for interception and water conservation. The interception and interception efficiency are the highest in the light rain events and it demonstrates best when two rain events happen in a internal of one day to two days.

Management of Pipe Discharge and Response of Rainfall. Rainwater is mainly discharged to the pipelines in China for a long time, which has many drawbacks: the rainfall in Kunming is extremely uneven, and most of the runoff is discharged as waste to rivers directly before it is absorbed by the soil. In addition, the frequency of rainstorm in the rainy season is very low, but with the large amount and short duration. Under this circumstance,pipes are often reluctant to deal with the flood caused by runoff from rapid rainfall in a short period.During the dry season, intense evaporation and long-period rainless result in a sharp increase in water demand. Due to the annual overdraft of soil water content, competitions for water between green spaces and people almost happen every year. So pipes are not the most cost-effective way to manage rainwater in Kunming.

\section{Goals and Strategies of Rainwater Management in Kunming Area}

Based on the comprehensive analysis of climate, soil, and underlying surface, this paper has drawn the main goals of rainwater management as collecting and utilizing rainfall in rainy seasons, which can be used to supply water in the soil,mitigate droughts in dry seasons and rebuild a healthy water circulation system. To achieve the above goals, the specific management strategies are as follows:

(1)Simulate Nature to Make the Land Work and Rebuild the Water Circulation System. Rainwater management methods include active and passive ways. Active management requires large investment and high maintenance costs. In developed countries, the payback time for the investment of a complex residential rainwater harvesting system is about 16 years[4]. Kunming, as an underdeveloped area ,passive management is worthy of promotion. The passive management is an 
ecological way of making the land work by inducting rainwater into the land to reconstruct rainwater system through planning and designing.

Nature manages rainwater by evaporation,infiltration and runoff. In a natural ecosystem within $10 \%$ of the impervious surface, $40 \%$ of rainfall is back to the atmosphere by evaporation and $50 \%$ infiltrates and is stored in the soil. Only about $10 \%$ of rainfall forms runoff discharged to rivers, lakes and oceans, participating another circulation[5].The total rainfall in Kunming is plenty, but various factors cause an imbalance regional water circulation.The soil is a "Living Filter" and a natural container in the city.If it can be made full use to recharge soil water through infiltrating reasonably, the surface runoff can be fully absorbed and stored in rainy seasons to increase soil water.Meanwhile water from reservoirs can be used to irrigate in dry seasons.Moreover soil gets fully moistened in rainy seasons, its demand for water naturally reduces. Therefore, simulating the process of the natural management of rainwater to improve soil infiltration capacity and to use green spaces to manage rainwater is a suitable,economical and ecological rainwater management strategy in Kunming area.

(2) Combine Green Spaces and Pipes to Manage Rainwater in the Split-flow Way.Use Different Green spaces to Intercept Rainwater From the Source.Reduce and Delay Rainwater Emission.Use Pipes to dispose overflow to Reduce Floods. The development of the city inevitably produces a mass of impervious surface and surface runoff. The traditional approach is to discharge runoff to pipes, which ignores the role of evaporation and infiltration in natural ecosystems, causing the waste of extremely valuable water resources and shortening the process of rainwater circulation.In recent years, the development of theory on rainwater management and the construction of sponge city have made people realize the powerful rainwater managing function of the green space. It is obvious that simply draining rain into the green is not a wise way to solve complex rain problems. Professor Stuart Echols of Pennsylvania State University proposed a split-flow method for rainwater management, which clearly sets out how to manage rainwater through green spaces diversion. It is proposed to combine the storage, infiltration, discharge and splitter together to form a self-regulating system to adapt different rain events. When the rain capacity stays stable,infiltration and emission can self-regulate based on the intensity and duration of rainfall.In light rain events, most of rainwater is led into the reservoir for further evaporation and first flush filtration.Evaporation, infiltration and discharge are evenly shunted in the moderate rain events. Most of runoff is drained during the rainstorm, and only a small fraction evaporates and infiltrates[5]. Split-flow theory treats evaporation and infiltration as important means of rainwater management, which are systematically designed to split water from the source and regulate water storage flexibly. The theory can better solve the difficulties in rainwater management caused by uneven rainfall which is exactly suitable in Kunming. In Kunming, the surface runoff is mainly from the frequent light rain events and occational rainstorms.Because of the large amount of green spaces,infiltration is more than one year return period precipitation.Coupled with interception of plants, if runoff is splitted into the green when it rains, it can be absorbed and purified.The occasionally overflow is discharged into rivers or reservoirs through the combination of diversion facilities and existing pipes. Therefore, the rainwater management in Kunming should be scattered treated from the source and the green space should be utilized to build a self-regulating system including store,infiltration and emission, which can collect and purify the runoff to reduce the initial pollution through the bioretention ponds. This system can also alleviate perennial water shortage of the soil through infiltration,meanwhile the overflow is drained through the spliter to avoid new rain problems. As the green space is treated as the rainwater management facility,working together with the splitter,the pipes and other combinations to reduce the peak runoff, original urban pipes are able to work more efficiently, greatly reducing floods.

(3)Implement the Suitable Practical Rainwater Management Technology with LID in Kunming Area. LID is achieved by decentralized, small-scale source facilities which used to control the runoff and pollution caused by rainstorms, so that the site can stay as close as possible to the natural hydrological circulation. The states in America have enacted the Best Practice of Rainwater Management Manuals according to the specific climatic and urban conditions, which roundly introduce the layout, structure and plant selection of various management facilities involved in LID 
technology.It can be directly used by the design and construction department.In 2014 in China, Ministry of Housing and Urban-Rural Development published a technical guide on construction of sponge city-Construction of LID Rainwater System for rainwater management. However,it is effective and instructional to formulate a suitabled Best Management Practices in Kunming to avoid rain and environmental problems cuasued by blind copy of overseas and other parts of China.

(4)Combination of Engineering and Artful Design. The urban green space is not only an important part in ecology, but also a public place for entertainment and education. Taking the green space as a rainwater management facility is to give it the ecological and social function rather than change the existing function.It is more than a rainwater management facility.Traditional drainage facilities pay more attention to function instead of aesthetics. The original cultural artistry and recreation function must be kept once the green space is used for rainwater management.Garden design techniques should be applied in rainwater design, so that the green can " be ecologically legible and easy to maintain, inspire public with rain-and-environment-related information system, be easy to enter, be multifunctional and with a unified visual characteristic and others "[6].Meanwhile,as an open rainwater management facility combining engineering and art design.it should have values of aesthetics,ecology,recreation,economy,culture and so on. Whether these values can be better achieved or not,it is still vital on evaluation of rainwater management facilities.

\section{References}

[1] Donglin You. Research on the Construction of Ecological City in Kunming, Yunnan Science and Technology Press(2003).

[2] Jiangang Ma,Jianwu Ma and Mei Lu, Research on Soil Infiltration Characteristics of Green Space in Park in Kunming, Journal of Southwest Forestry University, 2016 (3) :111-115.

[3] Statistics bureau of Kunming,Kunming Statistical Yearbook 2013, China Statistics Press(2013).

[4] Stuart Echols,Split-flow theory: Stormwater design to emulate natural landscape. Landscape and Planning 85 (2008) 205-214,Volume 85, Issues 3-4, 30 April 2008.

[5] Gould,John and Erik Nissen Petersen.rainwater Catchment Systems for Domestic Supply:Design,Constrtuction and Implementation.South Hampton Row,London:Intermediate Technology Publications Ltd.1999.

[6] Stuart Echols and Eliza Pennypacker, From Stormwater Management to Artful Rainwater Design. Landscape Journal. 27:2-08 ISSN0277-2426. 